journey was most dangerous. At this height it had rained, and the snow had become so soft that they often sank to the waist in it. In the rapid slopes, where they were forced to descend zigzag, the snow slipped from under their feet, but, after much care and fatigue, they arrived at the Grands-Mulets. A good meal, a denser air, and a milder temperature, soon restored them to their usual health. Towards 7 o'clock they came to Chamounix, where they received an enthusiastic welcome.

It had thus been proved that it was quite possible to live and make observations at those high altitudes. The greatest danger is in the violent storms that burst almost without notice, and which may become terrible tempests against which any temporary observatory would not stand. M. Richard says that the results of the observations will be published when the papers have been inspected and classified.

\section{THE PHOTOGRAPHIC CHART OF THE HEAVENS}

WE reprint from the Observatory for May the following article by the editors:-

The "Bureau du Comité international permanent pour l'exécution photographique de la Carte du Ciel" has published, amongst other more technical papers relating to this subject, one by Dr. Gill, of a very remarkable character, to which we wish to draw attention. Most of those who attended the Conference understood that the work in contemplation was to make a photographic chart of the heavens, to take pictures of the stars by photography, showing, with the greatest care, the appearance of the heavens as they are at the present time, in order that at a future time these pictures might be used, by comparison with other pictures taken under similar conditions or directly with the sky, to determine the many questions that could be dealt with in this way-to enable, in fact, the astronomer of the future to have the sky of his past and his present to deal with. That this was so will be seen from a consideration of the three following resolutions which were agreed to unanimously by the Conference :-

" 1 . The progress made in astronomical photography demands that the astronomers of the present day should unite in undertaking a description of the heavens by photographic means.

" 2. This work should be carried out at selected stations, and with instruments which should be identical in their essential parts.

" 3 . The principal objects are $(\alpha)$ to prepare a general photographic chart of the heavers for the present epoch, and to obtain data which will enable us to determine with the greatest possible accuracy the positions and the bright ness of all the stars down to a given magnitude (the magnitude being understood in a photographic sense to be defined); $(\beta)$ to provide for the best means of utilizing both at the present day and in the future the results of the data obtained by photographic means.'

These were the fundamental resolutions; others, recommended by the two sections into which the Conference divided, were adopted as explanatory of the first. Amongst these was one in which it was decided to take "a second series of plates down to the IIth magnitude, in order to insure greater precision in the micrometric measurement of the reference-stars, and render possible the construction of a catalogue." We have stated these fundamental resolutions at length as bearing on the question of a catalogue of stars, for the paper by Dr. Gill contains the astounding proposition of cataloguing no less than 2,000,000 stars; that is to say, Dr. Gill gravely and seriously. proposes the establishment of a Central Bureau, consisting of chief, assistants, secretaries, and a staff of measurers and computers, to take the photographs and measure them, and make a catalogue, the work to go on for twenty-five years at a cost of 250,000 francs, or $£ 10,000$, per annnm, or for fifty years at $\mathrm{I} 5 \mathrm{O}, 000$ francs.

It is quite true that this is only a proposition that Dr. Gill makes; but if such a proposition is possible in face of these direct resolutions of the Conference, it is quite time that everyone interested in the success of the work the Conference met to consider (that is, the photographic chart of the heavens) should bestir himself and see that the proposed work is not endangered by such astounding proposals.

To tack on to a work such as that sanctioned by the Conference-a work eminently practical, that has the support of all astronomers, and that has already been taken up by many of the Governments who were expected to join - a gigantic work such as Dr. Gill proposes, a work beside which that proposed by the Conference sinks into insignificance, would neither be fair to the Conference nor just to those Governments who have joined in the undertaking. The feature of the international scheme that makes it possible to obtain the assent of Government is that the work is proved to be practicable by experiment, and that it can be done at a moderate cost in something like five years, while the results are good for as long as the plates will last. To increase this work by extending it to, at the lowest computation of time, twenty-five and possibly fifty years, and to add enormously to the cost, would be to jeopardize the whole scheme.

Dr. Gill states that the actual state of astronomical science demands a catalogue of stars to the 1 ith magnitude. He thus raises the question on its merits; and we would liere state that it is more than possible that not only is there no need of such a catalogue, but that the use of such catalogues as he proposes has for ever ceased. The minds of some astronomers move in grooves, and it will, no doubt, never be conceded by them that catalogues can be superseded; they will die as they have lived, in the strong belief that the only way to use the stars is to catalogue them.

Till recently the knowledge we had of the stars was only to be gained from a written description of their brightness and position with regard to each other; hence the catalogue was an absolute necessity if we needed to know the number or brightness of certain stars in any part of the sky at any previous time; and we could only find this out if we had a catalogue of that time. Our catalogues of stars are all we have to show what has beer. observ'ed up to the present time; but when we have a photographic chart of the heavens, we have for our record not a catalogue, but a representation. That catalogues of stars such as are used for fundamental places will be always used goes without saying; the photographic plates themselves, and the four or five stars on each required as the fiducial points and for identification, will of course be catalogued; but, beyond this, to catalogue the stars on each plate, to measure them for the purpose only of getting their places written down, would be the most utter waste of time, labour, and money that it could enter the mind of man to conceive.

The proposition brought forward by Dr. Gill should be settled decisively so far as the proposition concerns the work proposed by the Conference. There can be no question that such a thing was never intended; had such a thing been thought of, we should have had a "Conference for discussing the best way of making a Catalogue of Stars by photography."

As this was not done, it can be done now; and if there is the great need of a catalogue of stars to the IIth magnitude felt by so many astronomers, as stated by Dr. Gill, it is a thing of so mush greater importance as far as cost and time are concerned, that it should be consiclered and dealt with entirely apart from the other work. A new Congress might discuss it ; the one which met in 1887 is not in any way committed to such a scheme. 